\title{
Patient's Adherence Towards Antihypertensive Medication and Life-Style Modification in Asmara, Eritrea
}

\author{
Daniel Tikue Asrat ${ }^{*}$, Brkti Abraham, Daniel Abraham, Filmawit Negassi, Habtom Mezgebo, \\ Solomon Mengisteab, Ghirmay Ghebreizgiabher, Frezghi Hidray
}

Department of Nursing and Public Health, Asmara College of Health Sciences, Asmara, Eritrea

Email address:

danitkku21@gmail.com (D. T. Asrat)

${ }^{*}$ Corresponding author

\section{To cite this article:}

Daniel Tikue Asrat, Brkti Abraham, Daniel Abraham, Filmawit Negassi, Habtom Mezgebo, Solomon Mengisteab, Ghirmay Ghebreizgiabher, Frezghi Hidray. Patient's Adherence Towards Antihypertensive Medication and Life-Style Modification in Asmara, Eritrea. Journal of Drug Design and Medicinal Chemistry. Vol. 6, No. 3, 2020, pp. 30-38. doi: 10.11648/j.jddmc.20200603.12

Received: August 29, 2020; Accepted: September 17, 2020; Published: December 16, 2020

\begin{abstract}
Hypertension is one of the major risk factors for coronary heart disease, stroke, heart failure, and end-stage renal disease and remains the main public health challenge. In Africa, 15\% of the population has hypertension [1]. According to the data from Health Information Management System (HIMS) of Eritrea the incidence of hypertension in Eritrea was 8305 in 2014. Poor adherence towards antihypertensive medication is the main problem of treatment failure and wastage of health care resource which leads to increased morbidity and mortality rate among hypertensive patients [2]. The aim of the study is to assess patient's adherence level towards antihypertensive medication and their life style modification in Halibet and Hazhaz Hospitals. This is Hospital based cross-sectional quantitative study. Sample size was determined using Krejcie \& Morgan formula. The sample size was 360 . Sample of 360 was collected by consecutive non probability method by approaching the patients during their follow up time those who fulfill the inclusion criteria. Pilot study was done in Halibet hospital. Morisky medication adherence scale was used to assess medication adherence rate. Data was entered and analyzed using statistics package for social sciences version 20. $P$-value $<0.05$ was considered as statistically significant. The ethical issue was dealt by obtaining a permission letter from the School of Nursing and given to the medical directors of both hospitals. The adherence rate of the respondents towards medication was $69.2 \%$. Among the respondents $71.7 \%$ had good adherence towards life style modification. Most of the participants were found to be adherent to their medication and life style modification that is $69.2 \%$ $\$ 71.7 \%$ respectively. Systolic and diastolic blood pressure was negatively associate with medication adherence at $p$ value $=0.004$ and 0.002 respectively. Age was significantly associated ( $\mathrm{p}$-value $=0.000$ ) with adherence to lifestyle modification. Recommendation health education should be given routinely to improve the rate of adherence toward their medication and life style modification by improving patient's knowledge and perception about hypertension and its consequence.
\end{abstract}

Keywords: Patient Adherence, Lifestyle Modification, Hypertension

\section{Introduction}

Hypertension is defined as having persistent, elevated systolic blood pressure of $140 \mathrm{mmHg}$ or above and/or diastolic blood pressure of $90 \mathrm{mmHg}$ or above. Untreated or suboptimal treated hypertension could lead to increased risk of morbidity and mortality due to cardiovascular, cerebrovascular, or renal diseases. Successful treatment of hypertension is important in reducing morbidity and mortality, as well as in controlling health care costs associated with these conditions [3].
Medication adherence is defined as "the extent to which the medication-taking behavior of a patient corresponds with agreed recommendations from a health care provider. [4] Uncontrolled hypertension is mainly caused by nonadherence to the antihypertensive drugs. Patients understanding their drug regimens help to improve their adherence thus will help prevent the complications of hypertension [5] however Poor adherence to medications is widespread especially in the treatment of chronic conditions such as hypertension leading to poor health outcomes and huge medical spending on drug-related morbidity. 
Lifestyle modification: The application of lifestyle modification is a suitable and necessary treatment for all patients diagnosed with hypertension. Combination of adherence to medications and lifestyle changes are vital to achieve the desired therapeutic goal. Major lifestyle changes that should be considered and that help in lowering the blood pressure adoption from Dietary Approach to Stop Hypertension (DASH) -eating strategy are dietary sodium decline, weight reduction in overweight and obese patient with habitual exercise, adequate intake of fruits and vegetables and decrease saturated fat intake. [6]

According to WHO report in 2009 Hypertension causes considerable morbidity and mortality worldwide, contributing 57 million (3.7\%) disability adjusted life years, and 7.5 million (12.8\%) premature deaths annually [7].

In Africa, $15 \%$ of the population has hypertension. It is the most powerful modifiable risk factor for stroke, which is itself a significant and growing public health problem in Sub-Saharan Africa (SSA) with an incidence similar to that in AfricanAmericans and higher than in Caucasian populations [1].

In Eritrea, the prevalence of hypertension among adults aged 15 to 64 years was $15.9 \%$ in the general population, with $16.4 \%$ in urban and $14.5 \%$ in rural areas, $17 \%$ of whom where males while $15 \%$ were females as per the national survey conducted in 2006 in which a total of 2352 people were participated [8].

According to the data from Health Information Management System (HIMS) of Eritrea, the incidence of hypertension in Eritrea was 8305 in 2014. Another recent report on analysis of data from HIMS also highlighted an increasing burden of non-communicable diseases (NCDs) in Eritrea, with the incidence of hypertension doubling in a periodic 6 years [2].

As reported by the World Health Organization, adherence to medication in patients with chronic diseases averages only around $50 \%$ in developed countries [9]. The situation is reported to be worse in developing countries due to poor accessibility to medications and health care services. Since Eritrea cannot be excluded from the developing countries and is equally affected by this lower rate of adherence to long term therapy.

Failure to adherence is a serious problem which is not only affect patients' health but also the health care system. Medication non-adherence in patients leads to substantial worsening of disease, death and increased health care costs. Therefore the study will provide current information on the patient's level of adherence towards their antihypertensive medication, life style modification and factors contributing to good and poor adherence. This study may inform and make aware the health care provider of the hospitals to design manual guideline for educating patients regarding their adherence towards their antihypertensive medication and lifestyle modification. Through that patients may increase awareness about importance of adherence to their medication and lifestyle modification on improving their blood pressure and health status. Beside this study may serve as a reference for other studies.

\section{Methodology}

\subsection{Study Design and Study Area}

The study was hospital based cross-sectional quantitative study. It was conducted at the hypertension and diabetes mellitus clinic of Hazhaz hospital and Halibet National referral Hospitals from February 2018 to May 2018. These two hospitals found in Zoba Maekel Asmara Eritrea and these are the only hospital which gives follow up care for hypertensive patients. Hazhaz hospital is located in North West of Asmara and Halibet hospital is located in the North East part of Asmara.

\subsection{Study Population}

The participants were known hypertensive patients who were registered and taken antihypertensive medication for more than three months. The age groups of the study participants were 18-85.

\subsection{Sampling Method and Sample Size}

There are about 5860 registered hypertensive patients in Halibet and Hazhaz Hospital who are taking antihypertensive medication regularly as outpatient follow-up. Among these patients the 3410 are from Hazhaz Hospital and the 2450 are from Halibet hospital. The study sample was calculated using Krejcie \& Morgan formula and it was 360 . The sample size for Halibet and Hazhaz hospital was calculated as per proportion of the population of each hospital and it was 151 and 209 respectively. Sample of 360 was collected by consecutive non probability method by approaching the patients during their follow up time those who fulfill the inclusion criteria. In this process, non-respondents and questionnaires which are not fully filled were excluded.

Formula for determining sample size.

$$
\begin{aligned}
& \left.\mathrm{S}=\mathrm{x}^{2} 2 \mathrm{NP}(1-\mathrm{P}) \div[\mathrm{d} 2(\mathrm{~N}-1))+\mathrm{XP}(1-\mathrm{P})\right] \\
& =3.841 \times 5860 \times 0.5 \times 0.5 \div[(0.05 \times 0.05(5859))+ \\
& (3.841 \times 0.5(0.5))] \\
& =5627.065 \div(14.6475+0.96025) \\
& =360
\end{aligned}
$$

$\mathrm{S}=$ required sample size

$\mathrm{X}=$ the table value of chi-square for one degree of freedom at the desired

Confidence level (3.841) $\mathrm{N}=$ the population size

$\mathrm{P}=$ the population proportion (assumed to be 0.50 since this would provide maximum sample size)

$\mathrm{d}=$ the degree of accuracy expressed as a proportion $(0.05)$

\subsection{Pilot Study}

A pilot study was done in order to recognize the weakness, strength and consistency of the questionnaire in Halibet National Referral Hospital at the hypertension unit on 36 hypertensive patients who come for their follow up care. The pilot study was done one week before the actual data collection. And the sample size for the pilot study was calculated as one tenth of the sample size of the research. 


\subsection{Validity and Reliability}

The validity of the tool was established as it was adopted from validated survey questionnaire (MMAS). The tool was modified and finalized according to the suggestion and recommendation of advisors and the research team. The reliability of the questioner was adopted from the MMAS Alpha Reliability $=0.83$, reflecting the good internal consistency and reliability

\subsection{Data Collection Method}

The research team conducted the study by approaching patients on their visit to Hazhaz and Halibet Hospitals of the hypertension unit for their follow up care. Validated survey questionnaire consisting of eight questions Morisky Medication Adherence Scale (MMAS) was used to assess patient's adherence level towards antihypertensive medication. Using a cutoff of 6 , its sensitivity or identifying low vs. higher adherer was estimated to be $93 \%$ and the specificity was $53 \%$. The MMAS- 8 has been demonstrated to have good concurrent and predictive validity and might function as a screening tool in outpatient settings with different patient groups. And the questions used for assessing patients adherence towards lifestyle modification was based on extensive literature review as there is no gold standard selfreporting measure of adherence to life style modification. The questionnaire was pretested for its sensitivity, comprehensibility, and appropriateness of language. The questionnaire was administered by the research group. The questioner included four sections which are close ended questions, section one socio demographic data; section two assessment of medication adherence level, section three assessments of patients clinical and medication characteristics, section four assessment of patient's adherence to life style modification. Questions were prepared in Tigrigna and an interview was done for respondents who were willing to answer but unable to fill due to illiteracy, eye problem or other difficulties.

Scoring tools: The aim of this scoring tool is to evaluate whether patients are adherent or not to their antihypertensive medication and life style modification.

Scoring for adherence to antihypertensive medication was based on MMAS scoring method. The MMAS eight question contains yes or no question and for each yes the score is 0 and for no is 1 . Patients who scored 6, 7 and 8 labeled as good adherence and those who scored 0 up to 2 labeled as poor adherence.

Scoring for adherence to life style modification was based on self-report MMAS. The questioner contains five questions with yes or no regarding life style modification. And those who scored 4/5 and 5/5 labeled as good adherence and those who scored $\leq 3 / 5$ labeled as poor adherence.

\subsection{Data Analysis}

The data was analyzed through SPSS (statistics package for social sciences) Version 20 at $95 \%$ CI. Data cleaning was performed to check for accuracy, consistency and there were no missed values during entry. Descriptive statistics was used to find mean, standard deviation and frequency of the results. Bivariate correlation and chi-square analysis method was used to find out the strength of the associations of each independent variable with the dependent variable. Correlation value 0 indicate no correlation, 1 indicate very strong positive correlation, $0-0.2$ indicate very weak positive correlation, 0.21 0.4 weak positive correlation, 0.41-0.6 moderate positive correlation, $0.61-0.8$ strong positive correlation, $0.81-1$ very strong positive correlation. If negative sign the same grading only differ it is negative correlation. All tests a p-value less or equal to 0.05 was considered as statistically significant.

\subsection{Ethical Considerations}

The ethical issue was dealt first by obtaining a permission letter from the School of Nursing, ACHS, and then taken to the Hazhaz and Halibet medical officer. Each study participant was adequately informed about the purpose, method and anticipated benefit of the study by the data collectors. Verbal and written consent was obtained from study participants and anonymity was maintained to ensure confidentiality. The responders' right to refuse or withdraw from the study was also respected fully. And all patients who were able to give informed consent by their signature (could be thumb signature) were invited to participate in the study.

\section{Result}

Table 1. Socio demographic characteristic of the study participants $(n=360)$.

\begin{tabular}{llll}
\hline Variables & & Frequency & Percent (\%) \\
\hline \multirow{2}{*}{ Sex } & Male & 164 & 45.6 \\
& Female & 196 & 54.4 \\
Age & $18-34$ & 6 & 1.7 \\
& $34-51$ & 54 & 15 \\
& $52-68$ & 177 & 49.2 \\
Marital status & 69-85 & 123 & 34.1 \\
& Married & 285 & 79.2 \\
& Single & 21 & 5.8 \\
& Divorced/widowed & 54 & 15 \\
Religion & Orthodox & 300 & 83.3 \\
& Catholic & 21 & 5.8 \\
Employment & Muslim & 32 & 8.9 \\
status & Protestant & 5 & 1.4 \\
& Other & 2 & 0.6 \\
Educational & Unemployed & 282 & 78.3 \\
status & Employed & 78 & 21.7 \\
& Illiterate & 128 & 35.6 \\
Monthly & Junior/secondary & 106 & 26.4 \\
income & College and above & 31 & 29.4 \\
\hline & Below 1000 Nkf & 207 & 8.6 \\
\hline & 1000-2000 Nkf & 123 & 57.5 \\
& $>2000 \mathrm{Nkf}$ & 30 & 34.2 \\
& & & 8.3 \\
\hline
\end{tabular}

A total of 360 patients who fulfilled the inclusion criteria were participated in the study. The age of the respondents ranged from 20 to 85 years old, with mean age of 62.90 years and standard deviation of 11.963 . The majority of the subjects were in the 52- 68 years old range. (54.4\%) of the respondent was females. More the three fourth of the sampled patients were orthodox religion. Two hundred eighty five reported as married and $57.5 \%$ of respondent reported as monthly income below thousand Nkf. Illiterate and unemployed accounted $35.6 \%$ and $78.3 \%$ of the respondent respectively. In detail of demographics 
characteristic was display in above table.

Table 2. Distribution of study participants response with respect to their adherence to antihypertensive medication ( $n=360$ ).

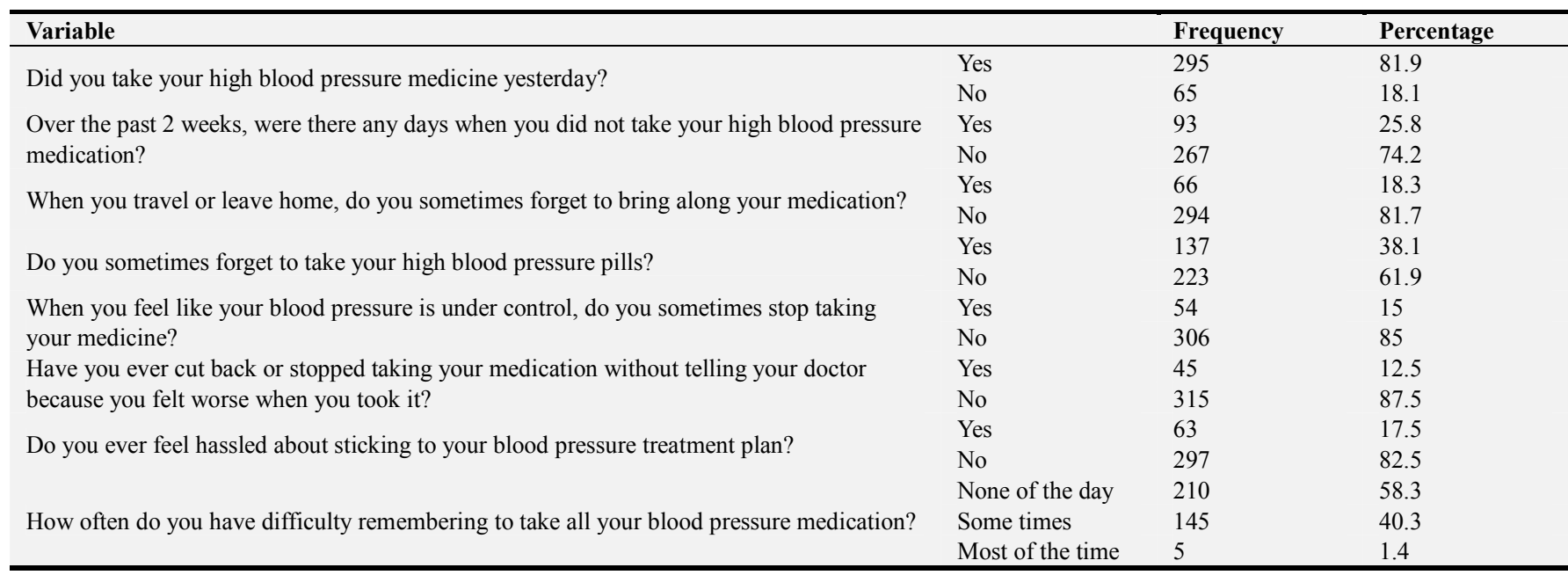

This table shows that, as per the Morisky scale, out of the 360 respondents, $38.1 \%$ were forgetting to take medicines, $12.5 \%$ were stopping medication on feeling worse, $40.3 \%$ had difficulty in remembering to some times to take all their blood pressure medication, $15 \%$ were stopping to take medication because they feel their blood pressure is under control. And $18.3 \%$ were forgetting to take their medication sometimes due to travel or leave home.

Table 3. Distributions of respondents were adherence level to their medication.

\begin{tabular}{|c|c|c|c|c|}
\hline Variable & Frequency & Percent (\%) & Mean score & Standard deviation \\
\hline Good adherence $(>=75 \%)$ & 249 & 69.2 & 60 & 10 \\
\hline Poor adherence $(<75 \%)$ & 111 & 30.8 & 0.2 & 1.9 \\
\hline
\end{tabular}

Table 3 show the adherence level of respondents to the antihypertensive medication. Out of all sample $69.2 \%$ of the respondent had good adherence and the remaining $30.8 \%$ had poor adherence to their medication. Mean score of the respondents was 6.2 and standard deviation 1.9.

Table 4. Medication and Blood pressure characteristic of respondents.

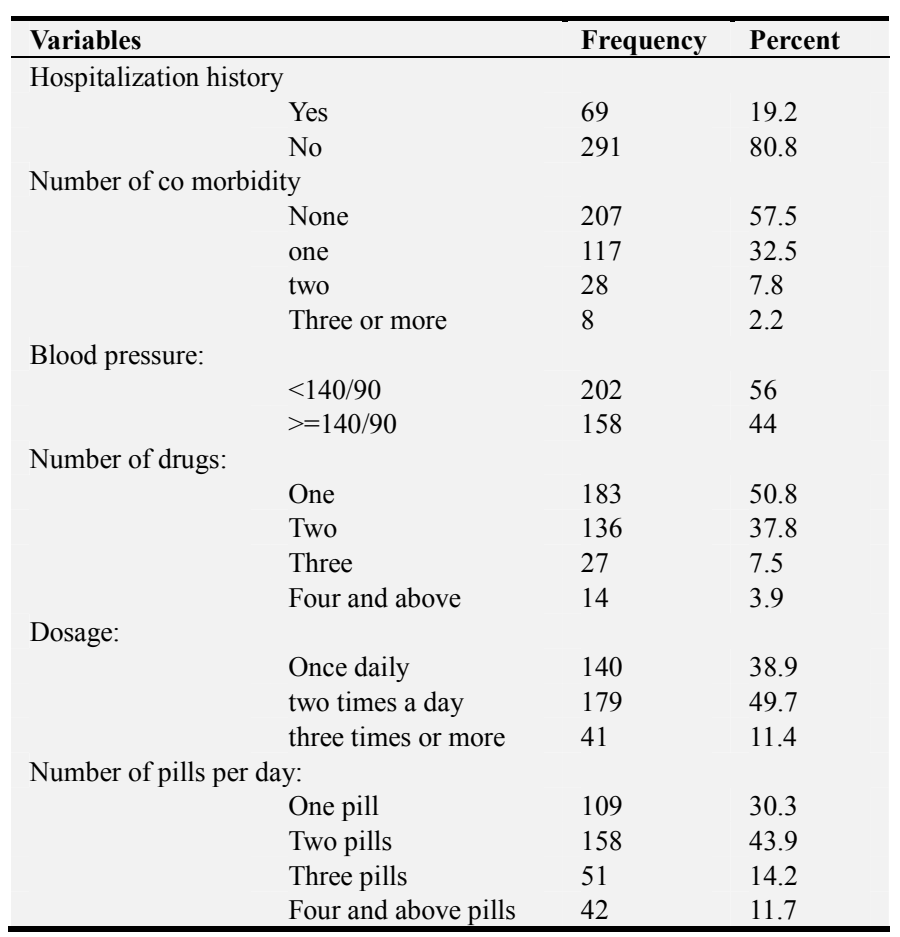

\begin{tabular}{lll}
\hline Variables & Frequency & Percent \\
\hline Do you have relative with hypertension & & \\
Yes & 128 & 35.6 \\
No & 232 & 64.4 \\
Duration of treatment in yrs.: & & \\
0.25-1yrs. & 30 & 8.3 \\
2-4yrs. & 92 & 25.6 \\
5-7yrs. & 70 & 19.4 \\
8-10yrs. & 79 & 21.9 \\
> 10yrs. & 89 & 24.7 \\
\hline
\end{tabular}

Table 4 show that only $19.2 \%$ of the respondents had history of hospitalization due to hypertension and more than half of the respondents that is $57.5 \%$ had co morbidities like heart disease, diabetes mellitus, and others. Majority of respondents had blood pressure $<140 / 90$. eighty nine $(24.7 \%)$ of the study subjects had taken the medication for more than ten years and only $8.3 \%$ of the respondents had taking the medication for less than one year. Among the subjects 35.6\% had relatives with hypertension. Regarding the medication information, $50.8 \%$ of the subjects were taking only one drug and $49.7 \%$ of the subjects were taking the medication two times a day. Out of the respondents $43.9 \%$ were taking two pills per day.

Table 5 Shows that among the respondent $83.9 \%$ were given health education regarding the lifestyle modification to control high blood pressure during their follow up care. More than half of the respondent were adherent to physical exercise and $68.9 \%$ were adherent for consumption of healthy diet. Only $4.2 \%$ and $12.2 \%$ of the respondent were practicing cigarette smoking and alcohol consumption 
respectively. Majority of the respondents were not using salt in their diet.

Table 5. Distribution of results regarding life style modification.

\begin{tabular}{llll}
\hline Variables & & frequency & Percentage \\
\hline \multirow{2}{*}{ Participation health education } & yes & 302 & 83.90 \\
& no & 58 & 16.10 \\
\multirow{2}{*}{ Practicing physical exercise } & yes & 207 & 57.50 \\
& no & 153 & 42.50 \\
\hline
\end{tabular}

\begin{tabular}{llll}
\hline Variables & & frequency & Percentage \\
\hline \multirow{2}{*}{ Consumption health diet } & yes & 248 & 68.90 \\
& no & 112 & 31.10 \\
Consumption of alcohol & yes & 44 & 12.20 \\
& no & 316 & 87.80 \\
\multirow{2}{*}{ Smoking } & yes & 15 & 4.20 \\
\multirow{2}{*}{ Salt intake } & no & 345 & 95.80 \\
& yes & 319 & 88.50 \\
& no & 41 & 11.50 \\
\hline
\end{tabular}

Table 6. Distribution of respondent's adherence to life style modification.

\begin{tabular}{|c|c|c|c|c|}
\hline Variable & Frequency & Percentage (\%) & Mean score & Standard Deviation \\
\hline Good adherence $(>=80 \%)$ & 258 & 71.7 & \multirow{2}{*}{4.1} & \multirow{2}{*}{0.99} \\
\hline Poor adherence $(<80 \%)$ & 102 & 28.3 & & \\
\hline
\end{tabular}

Table 6 Shows that the distribution of respondent's adherence to life style modification. Out of the respondents $71.7 \%$ had good adherence to life style modification (physical exercise, consuming healthy diet, avoiding alcohol consumption, avoiding smoking, and avoiding of salt in diet). mean score of the respondent was 4.1 and standard deviation 0.99 .

Table 7. Effect of selected socio-demographic and medication characteristics on adherence to antihypertensive treatment.

\begin{tabular}{|c|c|c|c|c|c|c|c|}
\hline \multirow{3}{*}{ Variables } & & \multicolumn{4}{|c|}{ Adherence Status } & \multirow{3}{*}{$\begin{array}{l}P \\
\text { value }\end{array}$} & \multirow{3}{*}{$\begin{array}{l}R- \\
\text { value }\end{array}$} \\
\hline & & \multicolumn{2}{|c|}{ Good adherence } & \multicolumn{2}{|c|}{ Poor adherent } & & \\
\hline & & Frequency & Percentage & Frequency & Percentage & & \\
\hline \multirow{2}{*}{ Sex } & Male & 111 & 67.68 & 53 & 32.32 & \multirow{3}{*}{0.195} & \multirow{6}{*}{.01} \\
\hline & Female & 138 & 70.4 & 58 & 29.4 & & \\
\hline \multirow{4}{*}{ Age in years } & $18-34$ & 4 & 66.7 & 2 & 33.3 & & \\
\hline & $35-51$ & 39 & 72.2 & 15 & 27.8 & \multirow{3}{*}{.982} & \\
\hline & $52-68$ & 120 & 67.8 & 57 & 32.2 & & \\
\hline & $69-85$ & 86 & 69.9 & 37 & 30.1 & & \\
\hline \multirow{4}{*}{ Educational level } & Illiterate & 85 & 66.4 & 43 & 33.6 & \multirow{4}{*}{.350} & \multirow{4}{*}{.040} \\
\hline & Elementary & 64 & 67.36 & 31 & 32.64 & & \\
\hline & Junior/seco ndary & 79 & 74.52 & 27 & 25.48 & & \\
\hline & College and above & 21 & 67.74 & 10 & 32.26 & & \\
\hline \multirow{3}{*}{ Occupation } & unemployed & 200 & 70.9 & 82 & 29.1 & \multirow{3}{*}{0.078} & \multirow{6}{*}{.018} \\
\hline & Employed & 49 & 62.8 & 29 & 31.2 & & \\
\hline & None & 136 & 65.7 & 71 & 34.3 & & \\
\hline \multirow{3}{*}{ Number of co morbidity } & One & 92 & 78.63 & 25 & 21.37 & \multirow{3}{*}{.739} & \\
\hline & Two & 14 & 50 & 14 & 50 & & \\
\hline & Three or more & 7 & 87.5 & 1 & 12.5 & & \\
\hline \multirow{2}{*}{ Blood pressure } & $<140 / 90$ & 159 & 78.7 & 43 & 21.3 & \multirow{2}{*}{.033} & \multirow{2}{*}{-.109} \\
\hline & $>=140 / 90$ & 90 & 56.9 & 68 & 43.3 & & \\
\hline \multirow{5}{*}{ Duration of treatment } & $0.25-1$ year & 21 & 70 & 9 & 30 & & \multirow{5}{*}{.037} \\
\hline & 2- 4 years & 61 & 66.3 & 31 & 33.7 & \multirow{4}{*}{.489} & \\
\hline & 5-7 years & 45 & 64.3 & 25 & 35.7 & & \\
\hline & $8-10$ years & 57 & 72.2 & 22 & 27.8 & & \\
\hline & $>10$ years & 65 & 73 & 24 & 27 & & \\
\hline
\end{tabular}

This table shows that out of the all variables only Blood pressure had significant negative association with medication adherence ( $\mathrm{r}=-0.109$, $\mathrm{p}$-value 0.033$)$.

Table 8. Effect of selected socio-demographic and medication characteristics on adherence to life style modification.

\begin{tabular}{|c|c|c|c|c|c|c|c|}
\hline \multirow{3}{*}{ Variables } & & \multicolumn{4}{|c|}{ Adherence Status } & \multirow{3}{*}{$\begin{array}{l}\mathbf{P} \\
\text { Value }\end{array}$} & \multirow{3}{*}{$\begin{array}{l}\text { R - } \\
\text { Value }\end{array}$} \\
\hline & & \multicolumn{2}{|c|}{ Good adherence } & \multicolumn{2}{|c|}{ Poor adherent } & & \\
\hline & & Frequency & Percentage & Frequency & Percentage & & \\
\hline \multirow{2}{*}{ Sex } & Male & 112 & 68.3 & 52 & 31.7 & \multirow{2}{*}{0.035} & \multirow{10}{*}{-.189} \\
\hline & Female & 146 & 74.5 & 50 & 25.5 & & \\
\hline \multirow{3}{*}{ Age in years } & $18-34$ & 6 & 100 & 0 & 0 & \multirow{3}{*}{0.000} & \\
\hline & $35-51$ & 45 & 83.3 & 9 & 16.7 & & \\
\hline & $52-68$ & 128 & 72.3 & 49 & 27.7 & & \\
\hline \multirow{5}{*}{ Religion } & Orthodox & 230 & 71 & 87 & 29 & \multirow{5}{*}{0.681} & \\
\hline & Catholic & 14 & 66.6 & 7 & 33.4 & & \\
\hline & Muslim & 25 & 78 & 7 & 22 & & \\
\hline & Protestant & 5 & 100 & 0 & 0 & & \\
\hline & Others & 1 & 50 & 1 & 50 & & \\
\hline
\end{tabular}




\begin{tabular}{|c|c|c|c|c|c|c|c|}
\hline \multirow{3}{*}{ Variables } & & \multicolumn{4}{|c|}{ Adherence Status } & \multirow{3}{*}{$\begin{array}{l}P \\
\text { Value }\end{array}$} & \multirow{3}{*}{$\begin{array}{l}\text { R - } \\
\text { Value }\end{array}$} \\
\hline & & \multicolumn{2}{|c|}{ Good adherence } & \multicolumn{2}{|c|}{ Poor adherent } & & \\
\hline & & Frequency & Percentage & Frequency & Percentage & & \\
\hline \multirow{4}{*}{ Monthly income } & $<1000$ & 151 & 73 & 56 & 27 & \multirow{3}{*}{0.768} & \multirow{7}{*}{.03} \\
\hline & $1000-2000$ & 87 & 70.7 & 36 & 29.3 & & \\
\hline & $>2000$ & 20 & 66.7 & 10 & 33.3 & & \\
\hline & None & 150 & 72.5 & 57 & 27.5 & \multirow{4}{*}{0.568} & \\
\hline \multirow{3}{*}{ Number of co-morbidity } & One & 85 & 72.6 & 32 & 27.4 & & \\
\hline & Two & 15 & 53.6 & 13 & 47.4 & & \\
\hline & Three or more & 8 & 100 & 0 & 0 & & \\
\hline \multirow{5}{*}{ Duration of treatment } & $0.25-1$ year & 22 & 73.3 & 8 & 26.7 & \multirow{5}{*}{0.576} & \multirow{5}{*}{-.03} \\
\hline & 2- 4 years & 62 & 67.4 & 30 & 32.6 & & \\
\hline & $5-7$ years & 53 & 75.7 & 17 & 24.3 & & \\
\hline & 8- 10 years & 63 & 79.7 & 16 & 20.3 & & \\
\hline & $>10$ years & 58 & 65 & 31 & 35 & & \\
\hline
\end{tabular}

This table shows the association between sociodemographic and medication characteristics of respondents with adherence to life style modification. There was statically significant association between sex and adherence to life style modification ( $\mathrm{p}$ - value 0.035$)$. There was a negative correlation between age and adherence to lifestyle modification $(\mathrm{r}=-0.189, \mathrm{p}=0.000)$. The other variables had no any significant association with adherence to life style modification.

Table 9. Comparison of the associations among adherence to medication, adherence to lifestyle modification, Systolic blood pressure and diastolic blood pressure.

\begin{tabular}{|c|c|c|c|c|c|}
\hline Variables & & $\begin{array}{l}\text { Adherence to } \\
\text { medication }\end{array}$ & $\begin{array}{l}\text { Adherence to life } \\
\text { style modification }\end{array}$ & $\begin{array}{l}\text { Systolic blood } \\
\text { pressure }\end{array}$ & $\begin{array}{l}\text { Diastolic blood } \\
\text { Pressure }\end{array}$ \\
\hline \multirow{2}{*}{ Adherence to Medication } & p-value & & 0.014 & 0.004 & 0.002 \\
\hline & r-value & & 0.129 & -0.150 & -0.165 \\
\hline \multirow{2}{*}{ Adherence to lifestyle Modification } & $\mathrm{p}$-value & & & 0.299 & 0.329 \\
\hline & r-value & & & -0.055 & -0.052 \\
\hline Systolic blood Pressure & p-value & & & & 0.000 \\
\hline
\end{tabular}

There was significant negative association between adherence score of patients and systolic blood pressure $(\mathrm{R}=$ $0.150, \mathrm{p}=0.004)$. Medication adherence score was also significantly associate with diastolic blood pressure. $(\mathrm{R}=-$ $0.165, \mathrm{p}=0.002$ ). There was positive significant correlation between systolic blood pressure and diastolic blood pressure $(\mathrm{R}=0.429, \mathrm{p}=0.000)$. Adherence to life style modification was significantly associated with adherence to medication $(\mathrm{R}=0.129, \mathrm{p}=0.014)$.

\section{Discussion}

Adherence is an important tool that can increase treatment effectiveness, however literature has shown that the rate of adherence in chronic disease like hypertension is very low and thus it is the main problem in the management of diseases which require long-term treatment like hypertensions. Poor adherence to medication and lifestyle modification are the main reasons for uncontrolled hypertension, serious complications and wastage of health care resources.

In this study, the adherence rate of the respondents to their medication was $69.2 \%$. It is higher than studies conducted in Ethiopia (64.6\%) [1], Pakistan (57) [10] and Malaysia (53.4) [9]. However it is lower than the medication adherence rate reported in developed countries because of awareness and living standard inequality.

Among the study subjects female and male had similar good adherence rate to medication that is $70.4 \%$ and $67.68 \%$ respectively. Whereas other study conducted in Ethiopia revealed that men were found to be less adherent when compared to women [11].

Majority of the subjects participated in this study were between the age group of 52-68 $(\mathrm{n}=177)$ and 69-85 (123) and they had similar good adherence rate $67.8 \%$ and $69.9 \%$ respectively. Whereas the age group of 18-34 were the least $(n=6)$ and good adherence rate was $66.7 \%$. In-contrast to this study conducted in Sunderland showed that majority of the respondent were in the age group 30-40 and had high adherence rate (82\%) [12]. when looking to the monthly income of the participants it was found that participants with high income were least adherent (46.67\%). The study also revealed the unemployed had good adherence rate of $70.9 \%$. The result shows that those with BP $<140 / 90$ $(78.7 \%)$ were observed to be more adherent to the medication. This is similar with the study conducted in Ethiopia which was $75.91 \%$ of the respondent with controlled BP were adherent to medication [1].

This study shows that subjects who had taken their medication for long duration (8-10 and >10 years) were found to be more adherent $72.2 \%$ and $73 \%$ respectively. Comorbidities can worsen the conditions of the patient and 
make them unable to adhere to their antihypertensive medications. In this study subjects those who had comorbidity had high adherence rate (78.63) where as $50 \%$ of those with two co-morbidities had good adherence.

In this study even though there were difference between adherence rate of the age, sex, religion, educational level, occupation, marital status and monthly income, and medication characteristics of the respondent there was no any statically signification association with adherence level of the respondents at $\mathrm{p}$ - value 0.05 . Blood pressure was significantly associated with medication adherence $(\mathrm{R}=0.109$, p-value 0.033).

This study overall adherence (including diet, exercise, smoking cessation, moderation of alcohol consumption, and health education) revealed that $71.7 \%$ of the respondents had good adherence rate to life style modification. In contrast study was done in Ethiopia reveal that only $23 \%$ adhere to life style modification [13]. A study conducted in Saudi found that only $4.2 \%$ of respondents were adherent to all types of lifestyle recommendations [14]. This difference might be explained by methodological factors where the final included a small sample of only female's participants.

This study revealed $83.9 \%$ of the subjects were given health education regarding lifestyle modification during their follow up care time. Health education is one of the factors which increase adherence rate.

This study revealed that among the respondents $57.5 \%$ where adherent to physical exercise. Parallel studies conducted in Israel and Ethiopia found $47.7 \%$ and $31.4 \%$ adherence, respectively $[15,13]$. The possible explanation could be related to cultural discrepancy and not have an organized system in living areas in sub Saharan countries similar to Eritrea.

Smoking is one of the important risk factors for CVDs as well as HTN. In this study almost all of the respondents (95\%) were not smoking cigarette. Findings related to stopping of smoking are in line with studies conducted in Bangladesh, Turkey, and Ethiopia, where majority of the respondents were found to be adherent $[15,17,13]$.

This study also showed that $88.3 \%$ of the respondent were adherent to avoiding of salt intake in their diet. Whereas study done in Ethiopia revealed that of dietrelated adherence was $69.1 \%$ [13]. In contrast, a study in Bangladesh found that majority $(65.5 \%)$ of the study participants did not follow a special dietary modification [18]. The dissimilarity between this study and the study done in Bangladesh could be due to the variation between the residence of study participants and nutritional lifestyle between the two countries.

In this study there was statically significant association between age of the respondent and adherence to life style modification ( $p$ value $=0.000$ ). Sex was also significantly associated with adherence to life style modification ( $p$ value 0.035 ). This study showed that $74.9 \%$ of the respondent who had good adherence to medication also had good adherence to lifestyle modification. This study showed that there was significant negative association between adherence score of patients and systolic blood pressure $(r=-0.019, p=0.039)$ this means as adherence score increase systolic blood pressure was decreasing or vice versa. Medication adherence score was also significantly association with diastolic blood pressure. $(\mathrm{r}=-0.115, \mathrm{p}=0.029)$. There was positive significant correlation between systolic blood pressure and diastolic blood pressure $(r=0.429, p=0.000)$ this means if one variable increase the other also increase or if one variable decrease the other also decrease.

\section{Conclusion}

Most of the participants $(69.2 \% \& 71.7 \%)$ were found to be adherent to their medication and life style modification respectively. The selected socio-demographic characteristics (sex, religion, educational status, monthly income, marital status) were not significantly associated with adherence to medication. Blood pressure was significantly associated with medication adherence. Age and sex was significantly associated with adherence to lifestyle modification. Factors like Duration of treatment, number of co-morbidity, dosage frequency were not significantly associated with adherence to medication and lifestyle modification.

\section{Recommendation}

Adherence Counseling and patient education about the disease and its treatment are important to improve adherence status of patients; so health education should be given routinely to improve the rate of adherence toward their medication and life style modification by improving patient's knowledge and perception about hypertension and its consequence. The hospitals should develop manual guidelines for patient education regarding adherence towards medication and lifestyle modification. A detailed and comprehensive health education should be given to the family members of the patient about the medication regimen and the life style modification that the patient expected to do. Health providers should encourage patients' adherence to medication and life style modification.

\section{Limitation of the Study}

Self-reported was used as the only method of measuring adherence. This method has the disadvantage of recall bias and eliciting only socially acceptable response and hence, may overestimate the level of adherence and only registered patients who come for follow up care were participated in the study so this study cannot represent hypertensive patients who were not registered. The study was quantitative cross sectional design conducted using questionnaire consisting of close ended questions that restrict the respondent's feedback. 


\section{Abbreviations}

ACHS: Asmara College of Health Sciences; MOH: Ministry of Health; WHO: world health Organization, SPSS: Statistical Package Social Science, HTN: Hyperbaton CVD: Cardiovascular Disease.

\section{Funding}

There was no source of funding for the study, for the authors or manuscript preparation.

\section{Conflict of Interest}

The authors declare that they have no competing interests.

\section{Authors' Contributions}

All authors participated in all phases of the study including topic selection, design, data collection, data analysis, interpretation and presentation. Daniel contributes to write this manuscript.

\section{Availability of Data and Materials}

The complete data set supporting the conclusions of this article is available from the corresponding author and can be accessed up on reasonable request.

\section{Acknowledgements}

We particularly want to express our deep gratitude and appreciation for the staff members of Halibet and Hazhaz hospital of the diabetic unit for their cooperation during data collection. We are thankful to the clients of Halibet and Hazhaz Hospital Diabetic Clinic, for agreeing to participate in this study as without them, this study would not have been conceptualized.

\section{References}

[1] Alemie, A. G., Ambaw, D. A., Mengesha, B. Z, B. Z., $\& W / J o h a n n e s$, M. S. (2012). Adherence to antihypertensive treatment and associated factors among patients on follow up at University of Gondar Hospital, Northwest Ethiopia. BMC Public Health, 12: 282 doi: 10.1186/1471-2458.

[2] Ministry of Health (2014). Cardiovascular Control Program: Annual report. Asmara, Eritrea.

[3] Jimmy, B. and Jose, J. (2011). Patient Medication Adherence: Measures in Daily Practice. Oman Journal of hypertension, 26 (3): 225-229.

[4] Sabaté E. Adherence to long-term therapies: evidence for action. World Health Organization; [Accessed Jul 2012]. [Updated 2003; cited May 2012]. Available from: http://apps.who.int/medicinedocs/en/d/Js4883e/6.1.3.html. [Google Scholar].
[5] Ahari, S. S., Biria, M., Heydari, H., Kamran, A., Malepour, A. (2014). Determinants of Patient's Adherence to Hypertension Medications: Application of Health Belief Model among Rural Patients. Ann Med Health Sic Res, 4 (6): 922-927. doi: 10.4103/2141-9248.144914

[6] Gabriel Uche Pascal Iloh, Agwu Nkwa Amadi, Godwin Oguejiofor Chukwuebuka Okafor, Augustine Obiora Ikwudinma, Frances Udoka Odu and Ezinne Uchamma Godswill-Uko. (2014) Adherence to Lifestyle Modifications among Adult Hypertensive Nigerians with Essential Hypertension in a Primary Care Clinic of a Tertiary Hospital in Resource-poor Environment of Eastern Nigeria. British Journal of Medicine \& Medical Research 4 (18): $3478-3490$.

[7] Dewhurst, M. J. and Walker, R. W. (2015). Hypertension in subSaharan Africa; prevalence, prescription, pitfalls and paradigms. Journal of Human Hypertension, 10.1038/jhh.2015.93.

[8] Gebremichael, A, A., Konia, A., Mebrahtu, G., Mound, J., Masjuan, M., Ghebrat, Y, Y. \&Nyarango Usman, (2006). The prevalence of hypertension and its relationship with obesity: results from national blood pressure survey in Eritrea. Journal of Human Hypertension, 20 (1), 59-65.

[9] Ahmad, N. S., Ramli, A., \& Paraidathathu, T. (2012). Medication adherence among hypertensive patients of primary health clinics in Malaysia. Patient preference and adherence, 6 (1): 613-622.

[10] Abbas, K., Afraid, MB. Hashmi, Sk., et al. (2007). Factors associated with adherence to antihypertensive treatment in Pakistan. PLoS ONE 2 (3): e280.

[11] Ahmed, M., Anuw, R., Froa, M., Gunasekaran, T., Kefale, B., \& Tadesse, E. (2015). An Assessment of Adherence of Patients to Anti-Hypertensive Medication and Factors for Non-Adherence in Oromia Region Adama Referral Hospital, Ethiopia. Global Journal of Medical Research, 1 (1); vergion 1.0 .

[12] Muhammad Umair Khan, Shahjahan Shah, and Tahir Hameed: 2014, Barriers to and determinants of medication adherence among hypertensive patients attended National Health Service Hospital, Sunderland: J Pharm Bioallied Sci. 2014 Apr-Jun; 6 (2): 104-108. doi: 10.4103/0975-7406.129175.

[13] Abel Tibebu, Daniel Mengistu, and Lemma Negesa: 2017, Adherence to recommended lifestyle modifications and factors associated for hypertensive patients attending chronic follow-up units of selected public hospitals in Addis Ababa, Ethiopia: 2017 Feb 24. doi: 10.2147/PPA.S126382, PMCID: PMC5338986, PMID: 28280305 .

[14] Elbur AI. Level of adherence to lifestyle changes and medications among male hypertensive patients in two hospitals in taif; Kingdom of Saudi Arabia. Int J Pharm Pharm Sci. 2015; 7 (4): 168-172. [Google Scholar].

[15] Danaei G, Finucane MM, Lin JK, et al. National, regional, and global trends in systolic blood pressure since 1980: systematic analysis of health examination surveys and epidemiological studies. Lancet. 2011; 377 (9765): 568-577. [PubMed] [Google Scholar].

[16] Akhter N. Self-Management among Patients with Hypertension in Bangladesh. Prince of Songkla University; Bangladesh: 2010. [Google Scholar]. 
[17] $\mathrm{Hu} \mathrm{H}, \mathrm{Li} \mathrm{G}$, Arao T. Prevalence rates of self-care behaviors and related factors in a rural hypertension population: a questionnaire survey. Int J Hypertens. 2013; 526949. [PMC free article] [PubMed] [Google Scholar].
[18] Azadbakht L, Fard NRP, Karimi M, et al. Effects of the dietary approaches to stop hypertension (DASH) eating plan on cardiovascular risks among type 2 diabetic patients: a randomized crossover clinical trial. Diabetes Care. 2011; 34 (1): 55-57. [PMC free article] [PubMed] [Google Scholar]. 